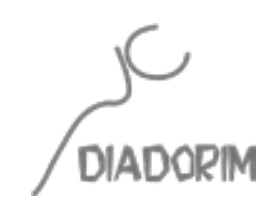

\title{
FIAMA EM CENA VIVA
}

\author{
Maria Silva Prado Lessa ${ }^{1}$
}

\section{RESUMO}

Parece-nos necessário um exercício de aproximação ao aspecto cênico da obra de Fiama Hasse Pais Brandão a partir da manifestação de uma crença no caráter performático da voz poética, traço percebido tanto em produções pertencentes ao universo teatral quanto em seus poemas. Nesta incursão à qual nos lançamos, a relação entre poesia e teatro ou poesia e drama é tomada a partir da leitura da estrutura de uma "recitação poética" incluída no livro de estreia da autora, Em cada pedra um voo imóvel (1958), intitulada "Luar e sal". Neste primeiro momento de sua escrita, o que vemos é a aposta num "teatro da voz" - como Jorge Fernandes caracterizará a sua poesia em Cenas vivas (2000) -, promovido pelo minimalismo do gesto e pela redução do espaço cênico ao eco das falas dos diversos personagens. Dessa forma, no livro de 1958, a "cenografia" se mostra uma primeira maneira de alçar o poema à qualidade de lugar, como apontará Eduardo Prado Coelho, quando sugere que "Poesia 61" formulará uma "concepção topológica do texto como lugar onde o sentido se produz" (1976, p. 265).

PALAVRAS-CHAVE: Fiama Hasse Pais Brandão; poesia; teatro; voz; performance.

\section{ABSTRACT}

Considering the manifestation of a belief in a performing aspect of the poetic voice in Fiama

1 Doutoranda em Literatura Portuguesa da Universidade Federal do Rio de Janeiro, Professora Substituta de Literatura Portuguesa na Universidade Federal do Rio de Janeiro. E-mail: mariasplessa@, gmail.com.

Recebido em: 29/03/2018

Aceito em: 29/06/2018

(cc) BYNAC

A revista Diadorim utiliza uma Licença Creative Commons - Atribuição-NãoComercial 4.0 Internacional (CC-BY-NC).

Diadorim, Rio de Janeiro, vol. 20, n. 1, p, 51-60, jan-jun. 2018. 
Hasse Pais Brandão's work, approximating her literary work and its scenic expression reveals a relevant exercise in what regards her poems as well as her written production related to theatrical features. The relation between poetry and theatre or poetry and drama is proposed by reading the structure of a "poetic recitation" called "Luar e sal", which is included in Em cada pedra um voo imóvel (1958), the first book of the Portuguese writer. In this initial moment of her writing, it is possible to notice a pursuit of a "theatre of the voice" - as Jorge Fernandes characterizes Fiama's poetry in Cenas vivas (2000) -, fostered by the minimalism of the gesture and by the reduction of the scenic space to the echo of diverse characters' speeches. Therefore, in the book written in 1958, the sceno-graphy shows itself as a first move of lifting the poem to the state of place, as Eduardo Prado Coelho would point out when suggesting that "Poesia 61" formulates a "topological understanding of the text as a place where the meaning is formulated" (1976, p. 265).

KEYWORDS: Fiama Hasse Pais Brandão; poetry; theater; voice; performance.

O aspecto cênico da obra de Fiama Hasse Pais Brandão é assinalado por Jorge Fernandes da Silveira, em seu comentário ao livro Cenas vivas, publicado em 2000, como a manifestação de um "teatro da voz". Silveira afirma que "nos seus textos, porque são muitas as citações, a escrita, como se em cena verbal aberta, exibe exemplarmente a intertextualidade" (SILVEIRA, $2000, \mathrm{~s} / \mathrm{p}$ ). Para além do título do volume, que aponta de partida para a relação entre poesia e cena, o traço teatral que a obra de Fiama apresenta residiria no seu jogo de vozes, na possibilidade de pôr múltiplos textos em diálogo uns com os outros.

A comparação entre a poesia intertextual de Fiama e o teatro é motivada, especialmente, pela expressiva produção dramática da autora que, além de poeta, foi tradutora de peças de autores como T. S. Eliot, Bertolt Brecht e Garcia Lorca, bem como autora de dramas como "O Cais" (1958) e "Noites de Inês/Constança" (1996), tendo visto peças suas representadas sobre os palcos portugueses ou na televisão, conforme ressalta Eugénia Vasques no artigo "O manifesto teatro de Fiama" (2005). O caminho dramático foi traçado na obra de Fiama, portanto, antes mesmo do potente Morfismos de Poesia 61 e se faz presente desde o seu primeiro livro, intitulado Em cada pedra um voo imóvel (1958) - escrito quando a autora tinha 19 anos, em 1957. Eugénia Vasques, defende que, em seu livro de estreia, apresenta-se "uma escrita que é já teatro" (VASQUES, 2005, p. 20), afirmando, ainda, que a autora "entrou para o teatro pela porta radical da poesia" (Idem, p. 19).

Em "Recitações dramáticas", seção inicial do livro de 1958, encontra-se um conjunto de oito textos que o leitor identifica, desde o primeiro momento, como pertencente ao universo do teatro, são eles "O mito e o homem", "Luar e sal", "Só havia quatro caminhos", "O trigo não morre", "A criança dos olhos parados", "Os moinhos trágicos", "O poente" e "Ainda era cedo". A expressão do título da seção - "recitações dramáticas" - parece prenunciar, já, a relação apontada por Jorge Fernandes da Silveira entre a intertextualidade e a dramaticidade nos poemas de Fiama, uma vez que, por meio da expressão "recitação", a autora proporia a "repetição de citações" de textos que sulcaram o imaginário poético, fazendo de sua obra 
o local em que se encontram e se costuram. Ao tomar o poema como canal de passagem ${ }^{2}$ de uma voz e abordando a performance da recitação poética, Éric Benoit, em Dinamiques de la voix poétique, sugere que o termo "recitação", para que seja lido em "toda sua substância sensível" (BENOIT, 2016, p. 70), deve ser decomposto em "re-citação", que significaria

a retomada de uma citação, o re-encarregar-se pessoalmente de uma citação. Uma citação, etimologicamente, é aquilo que suscita um movimento. O verbo latino cieo, civi, ciere, citum (mesma raiz do grego kio, kineo, que encontramos em "cinética") significa: pôr em movimento [...]; dai: excitar, suscitar, provocar, fazer vir, chamar, convoca, proclamar. A citação, ou a re-citação, é aquilo que nos incita, que nos põe em movimento, nos faz agir. [...] [P] rovoca em nós moções e emoções. (BENOIT, 2016, p. 70, tradução nossa).

O título da seção sugere, ainda, uma mescla entre a performance oral do texto poético que caracteriza a ação de "recitar" um poema e o caráter dramático que é trazido pelo segundo termo da expressão, característica que parece mais presente nas cenas que a compõem. Dessa maneira, as possibilidades de aproximação entre poesia e teatro expressas já no primeiro momento da produção de Fiama - para além do jogo de cena intertextual apontado por Silveira, no qual

\section{Figura SEQ Figura 1 * ARABIC 1 - Folha de rosto de "Luar e sal" \\ LUAR E SAL PERSONAGENS: \\ O Pescador \\ O Salineiro \\ A Varina \\ Coros I e II de Pescadores \\ Coro III de Varinas \\ Todos os personagens vestem trajos populares}

textos alheios figurariam como personagens de um mesmo drama passado sobre o palco do poema - emergem também nos modos de perceber como a autora funda seu teatro sobre uma aposta na performatividade inerente à "passagem" do verbo poético, uma vez que as cenas de "Recitações dramáticas" têm, nas falas dos personagens, sua ação predominante. Tomando como ponto de partida a estrutura dos textos do livro de estreia e a relação destes com sua produção lírica, sugerimos a leitura de um excerto de "Luar e sal", a segunda peça de Em cada pedra um voo imóvel:

$\begin{array}{ll}\text { Coro III } & \text { O mar hoje está indecifrável } \\ \text { Coro I } & \text { Está calmo. } \\ \text { Coro II } & \text { Está calmo. } \\ \text { O pescador } & \text { Mas a minha rede é velha e as tábuas do meu barco têm fendas } \\ \text { Coros I e II } & \text { És velho. } \\ \text { Coro III } & \text { És velho. }\end{array}$

2 O termo utilizado por Benoit é "relais de voix" (BENOIT, 2016, p. 49)..

Diadorim, Rio de Janeiro, vol. 20, n. 1, p, 51-60, jan-jun. 2018. 


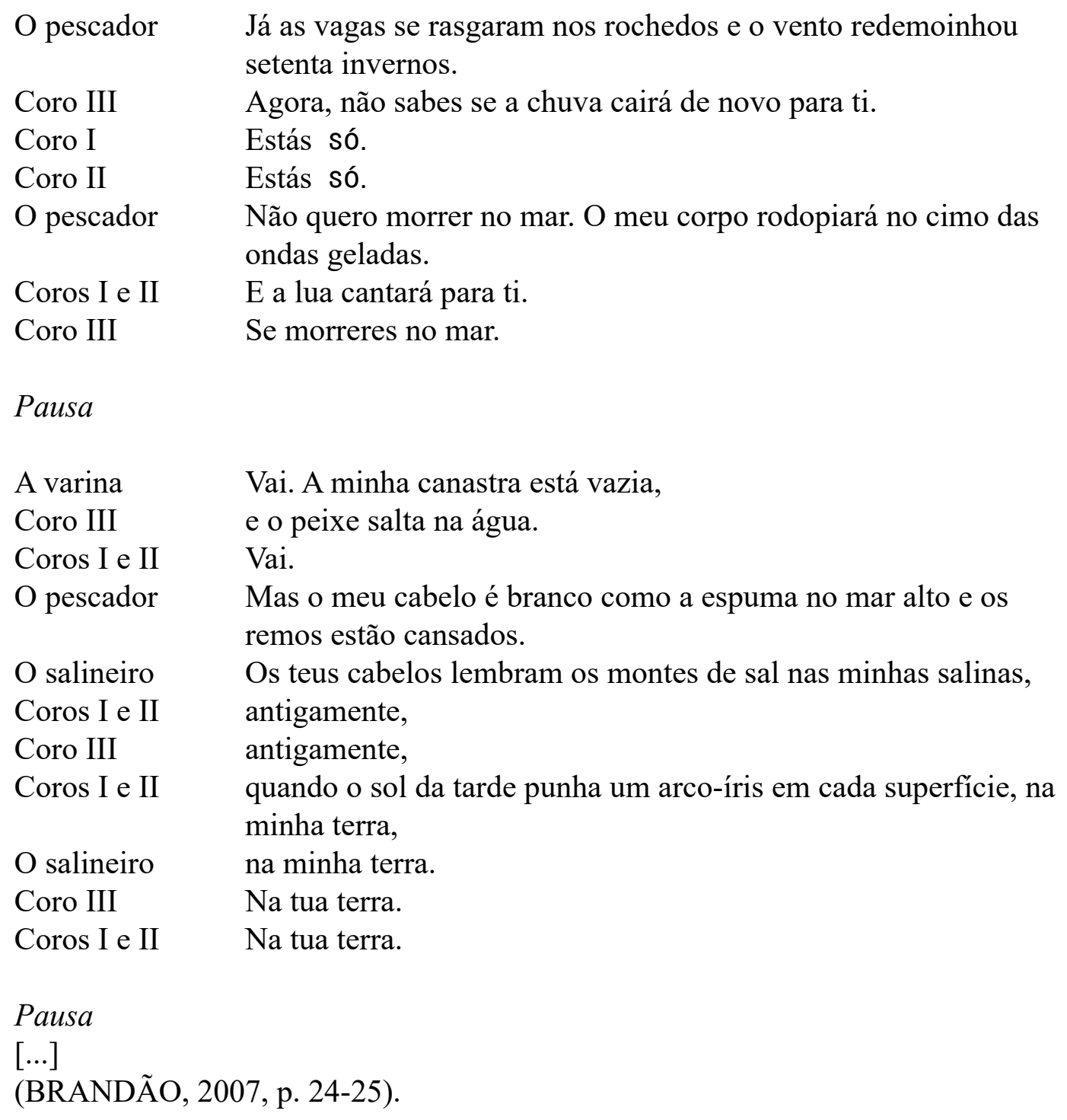

Como é possível observar, Fiama estrutura o texto como prototípica e tradicionalmente dramático, padrão que se repetirá em todos os textos da primeira seção de Em cada pedra um voo imóvel. Antes de cada cena, há pequenas didascálias, com uma lista de personagens e com curtas descrições de seu vestuário e do cenário a ser utilizado. De todas as peças, participam coros que, como consta na primeira página da seção dos textos teatrais, devem ser compostos por três vozes cada (BRANDÃO, 2007, p. 16). Ao longo do texto, faz-se a devida indicação das falas dos personagens, além da inclusão de brevíssimas rubricas que indicam pausas entre sequências dialógicas que, em apenas um dos textos, apontam aos atores a execução de pequenos e contidos gestos corporais. Com os movimentos sobre o palco reduzidos ao extremo, a ação predominante exercida ao longo das oito "recitações dramáticas", como se lê em "Luar e sal", é a enunciação, isto é, os personagens que a autora dispõe sobre o palco atuam sobretudo no nível da fala: eles não andam, não gesticulam, não têm nem mesmo uma entonação de voz sugerida por meio das rubricas.

Somente em "A criança dos olhos parados" as notas conduzem a ação dos atores sobre o 
palco, como nas rubricas iniciais em que se lê:

\author{
Dia de verão. Uma intensa claridade dourada dá vida própria ao ambiente. \\ A Criança brinca. A Pessoa Crescida não brinca. \\ O sol é sempre sol. \\ A hora, qualquer. \\ A Criança para de brincar e olha o céu pensativa. (BRANDÃO, 2007, p. 38).
}

Nos demais textos, as observações de autor se restringem a apontamentos de "Pausa", que conduzem o silêncio entre os personagens. As pequenas cenas que compõem a primeira parte do livro de estreia de Fiama, portanto, devem ser entendidas mais como "recitações", como acusa o título da seção, do que propriamente como encenações dramáticas, uma vez que a atuação se restringe à declamação de um texto, ou à leitura em voz alta de versos de poemas.

Nesse sentido, se a primeira poesia de Fiama é marcada pela antidiscursivdade, em que se experimenta “o isolamento da palavra, a destruição do hábito linguístico" (MARTELO, 2010, p. 128), poderíamos dizer que o teatro que apresenta nesse livro é caracterizado pela anti-ação, por uma antidramaticidade em que se destrói o hábito dos gestos, uma vez que a ação que se passa fora do nível da articulação vocal é mínima e pontual - restringindo-se, em "A criança dos olhos parados", a apenas duas rubricas com indicações como "A Criança brinca. A Pessoa Crescida não brinca" (BRANDÃO, 2007, p. 38), ou "A Criança ri e canta baixinho" (idem, p. 38). Trata-se, portanto, de um "teatro de vozes" (VASQUES, 2005, p. 21), como o chamam Eugénia Vasques e Jorge Fernandes da Silveira, assente na "força designativa" (MARTELO, 2010, p. 128) do verbo poético.

As "Recitações dramáticas" parecem, nesse ponto, trazer ecos de "O marinheiro", "drama estático em um quadro" de Fernando Pessoa. Neste, figuram três veladoras diante de um caixão no qual jaz uma donzela. Sentadas uma ao lado da outra, as personagens permanecem num estado de quase paralisia e veem o gesto como uma ruptura indesejável, conforme declara uma das veladoras: "Não, não vos levanteis. Isso seria um gesto, e cada gesto interrompe um sonho..." (PESSOA, 1985, p. 442). A ação, portanto, consiste unicamente no longo diálogo que travam, o qual, de estrutura composicional do drama, é elevado à categoria de tema principal deste. Assim, as personagens dialogam a respeito do próprio diálogo e dos efeitos da fala e da escuta:

A MESMA [PRIMEIRA] — Que foi que dissestes e que me apavorou?... Senti-o tanto que mal vi o que era... Dizei-me o que foi, para que eu, ouvindo-o segunda vez, já não tenha tanto medo como dantes... Não, não... Não digais nada... Não vos pergunto isto para que me respondais, mas para falar apenas, para me não deixar pensar... [...] Devíamos já ter acabado de falar... Há tempo já que a nossa conversa perdeu o sentido... O que é entre nós que nos faz falar prolonga-se demasiadamente... [...] [a]h, não me abandoneis... Falai comigo, falai comigo... Falai ao mesmo tempo do que eu para não deixardes sozinha a minha voz... Tenho menos medo à minha voz do que à ideia da minha voz, dentro de mim, se for reparar que estou falando...

Diadorim, Rio de Janeiro, vol. 20, n. 1, p, 51-60, jan-jun. 2018. 
TERCEIRA - Que voz é essa com que falais?... É de outra... Vem de uma espécie de longe...

PRIMEIRA — Não sei... Não me lembreis isso... Eu devia estar falando com a voz aguda e tremida do medo... Mas já não sei como é que se fala... Entre mim e a minha voz abriu-se um abismo... (PESSOA, 1985, p. 449-450).

Para além da centralidade da voz como tema do discurso e como matéria de construção dramática, é preciso ressaltar que, assim como as "Recitações" de Fiama, o drama de Pessoa é pontuado pela rubrica “(uma pausa)” (PESSOA, 1985, p. 441-449), que indica sucessivas pausas entre as falas das personagens, comentário que comentário recai, especialmente, sobre suas vozes e não seus movimentos no palco onde se passa a peça. Além disso, conforme observado nos textos de Fiama em questão, as ações corporais das personagens de "O Marinheiro" são apontadas em raros momentos, por indicações que sugerem apenas duas mínimas alterações em suas posturas e que recaem seja sobre sua inflexão de voz seja sobre a direção de seus olhos:

SEGUNDA - Para quê?... Fito-vos a ambas e não vos vejo logo... Pareceme que entre nós se aumentaram abismos... [...] Eu devia agora sentir mãos impossíveis passarem-me pelos cabelos - é o gesto com que falam das sereias... (Cruza as mãos_sobre os joelhos. Pausa). Ainda há pouco, quando eu não pensava em nada, estava pensando no meu passado.

(PESSOA, 1985, p. 443, grifo nosso).

SEGUNDA - Sim, falar-vos-ei mais dele. Mesmo eu preciso de vo-lo contar. À medida que o vou contando, é a mim também que o conto... São três a escutar... (De repente, olhando para o caixão, e estremecendo). Três não... Não sei... Não sei quantas...

TERCEIRA - Não faleis assim... Contai depressa, contai outra vez... Não faleis em quantos podem ouvir... Nós nunca sabemos quantas coisas realmente vivem e veem e escutam... Voltai ao vosso sonho... O marinheiro. O que sonhava o marinheiro?

SEGUNDA (mais baixo, numa voz muito lenta) - Ao princípio ele criou as paisagens, depois criou as cidades; criou depois as ruas e as travessas, uma a uma, cinzelando-as na matéria da sua alma - uma a uma as ruas, bairro a bairro, até às muralhas dos cais de onde ele criou depois os portos...

(PESSOA, 1985, p. 446, grifos nossos).

Além de assumirem um papel de destaque, é possível perceber como as falas dos personagens de Fiama estão, por vezes, ligadas às falas dos coros por um mecanismo que poderíamos facilmente identificar ao enjambement, próprio do universo da poesia, o qual sugere que os personagens compartilham com os coros as mesmas falas que se costuram ao longo das sequências, interrompidas pela "pausa" da autora. Em "Luar e Sal", tal estratégia pode ser notada na mistura entre as falas da Varina e do Salineiro com a dos coros: 


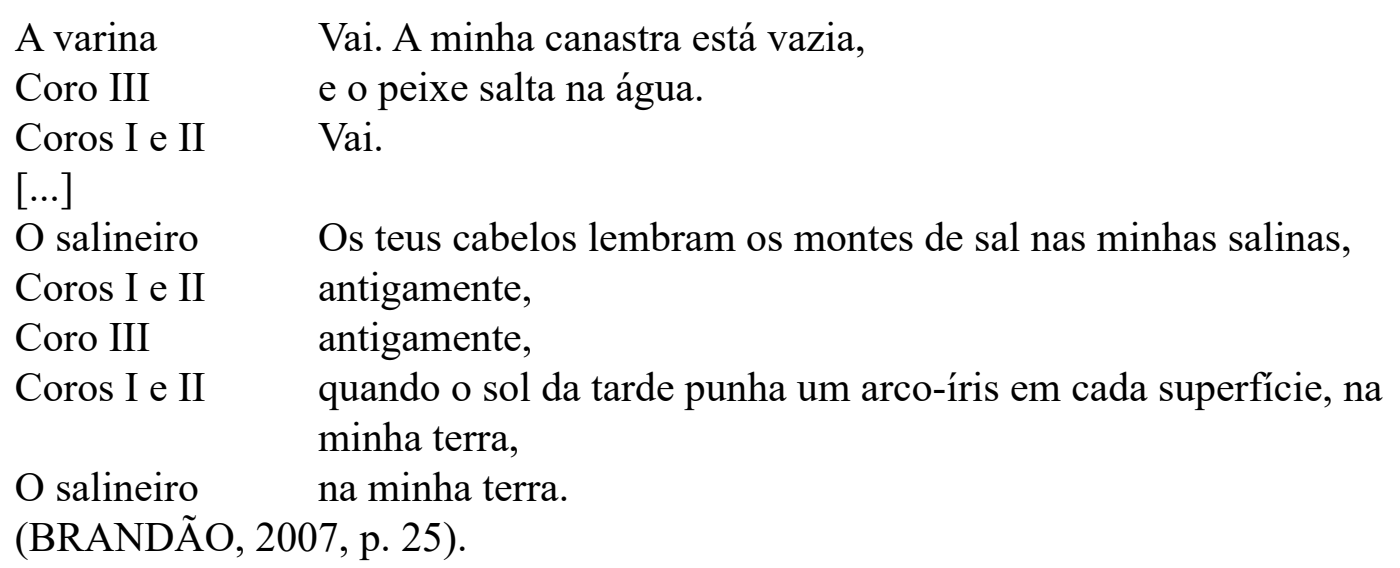

No fragmento acima, pode-se perceber como as falas dos personagens são compartilhadas com os três coros, costurando-se entre as diferentes vozes no palco. Assim, ao invés de se apresentarem em uma posição distanciada da ação, tecendo comentários a respeito dos diálogos entre os diferentes personagens, como se esperaria num uso tradicional desse elemento teatral, os coros parecem contribuir para a apresentação de pequenos monólogos polifônicos, nos quais julgamos ouvir um mesmo sujeito que se fragmenta em diversas vozes - como ocorre especialmente com as da Varina e do Salineiro complementadas pelas vozes por si só plurais dos três coros.

O coro é, portanto, elemento central das "Recitações dramáticas". Sua presença em todos os textos parece reforçar a potência da palavra a ecoar pelo espaço cênico, uma vez que as falas a ele destinadas ocupam a maior parte das composições, sem exceção. Ao contrário do que se passava no teatro grego, no qual o coro era tomado como elemento fundamental da representação, a sua inserção no teatro contemporâneo é inteiramente opcional, sendo percebida como um fator de comprometimento da verossimilhança e de ruptura na progressão dramática das cenas. Nos textos de Fiama, o coro parece apontar certa presença da voz de um eu lírico, uma vez que, em sua fala anônima a se misturar às falas das personagens, emerge um indício de onipresença própria daquele responsável pela disposição dos diversos elementos em cena e pela condução dos dramas. Assim, se, por um lado, os coros representam um aprofundamento da "antidramaticidade" em sua ruptura com a ilusão da representação teatral, por outro, retomam uma característica da tragédia grega, cujo coro, aponta Patrice Pavis, "revela que a ação era originalmente recitada e falada no teatro, ao invés de encarnada e representada por meio de diálogos entre dois ou mais personagens" (PAVIS, 2011, p. 134).

Assim como um narrador épico de Brecht - autor que teve obras traduzidas para o português por Fiama -, a voz de um eu lírico parece se fazer ouvir sob a enunciação dos coros a criar um novo nível dramático e a interromper a progressão mimética, que, no caso das recitações da autora de Morfismos, instaura um nível próprio da dicção lírica. Suas composições se revelam, 
principalmente, como poemas transformados em cenas cujas brechas, ou cuja "fissura do verso" (BRANDÃO, 2010, p. 32), se abrem em solidariedade às muitas vozes convocadas. Dessa forma, a transposição dramática de um texto lírico dá a outros personagens a possibilidade de falar por si e de se auto-apresentar.

Eugénia Vasques sublinha que, no primeiro momento da poesia de Fiama, manifestam-se três qualidades: “uma vocação para a revolta, uma vocação para a teoria e uma vocação [...] que é a de procurar para a escrita uma experimentalidade laboratorial mergulhada na materialidade da cena teatral" (VASQUES, 2005, p. 20). A migração da poesia para um teatro de palcos quase nus, com personagens que não se movem, provoca um esvaziamento visual da cena e uma consequente emergência das palavras como centro da ação. A estruturação de poemas em cenas teatrais e a singular utilização do coro, portanto, remetem a atenção dos espectadores e leitores de teatro exclusivamente para as falas, além de provocarem a sensação de estranhamento e de suspensão das convenções cotidianas, por meio da recusa do "efeito de realidade" e da criação de um sistema de regras próprias em que a palavra assume um papel genesíaco.

Fiama parece partir, já em sua primeira obra, de uma concepção da palavra poética baseada no poder de ação da própria linguagem, movimentada pela voz de um eu lírico capaz de sair momentaneamente do foco da cena para acolher múltiplas dicções, conforme ocorre na circulação das falas dos coros e dos personagens. Tal perspectiva parece atravessar sua obra, seja em seu caráter intertextual, como sublinhado por Silveira, seja na defesa de que a palavra tem poder criador, como teoriza em versos de "A voz, crescente", poema de (Este) Rosto (1970): "A própria fala cria / o objecto e separa-o / do silêncio" (BRANDÃO, 2010, p. 22); e de "Canto do canto", de Cantos do canto (1995): "Depois de a Voz ter o dom da cosmogénese / todos os cantos puderam ser cantados, / desde o bíblico ao franciscano canto / e aos poemas a esmo dos poetas" (idem, p. 125).

Seria possível, portanto, traçarmos um caminho que una a sua poesia à sua produção teatral tendo em vista o caráter de "ação revolucionária" assumido pela palavra, como caracteriza Jorge Fernandes da Silveira. Nesse sentido, a ideia proveniente do campo do teatro, que pensa a si mesmo como um processo ativo e progressivo de significação, parece, também, presente na obra poética de Fiama, uma vez que seu trabalho com a linguagem se revela na descoberta ativa e progressiva da palavra. Concebendo o discurso lírico como ato, sua poesia vai ao encontro da ideia de que o discurso dramático é dotado de força performática, com "poder de, simbolicamente, levar a cabo uma ação" (PAVIS, 2011, p. 103), como afirma Pavis. Assim como em "O Marinheiro" o diálogo, o discurso nas cenas de "Recitações dramáticas" é alçado à categoria de ação principal e, como sugere o teatrólogo francês,

o discurso teatral [ou dramático] é o local de uma produção de significante no nível da retórica, dos pressupostos e da enunciação. Por isso, não tem como única missão representar a cena, porém contribuir para representar-se a 
si mesmo como mecanismo de construção da fábula, da personagem e do texto (PAVIS, 2011, p. 103).

A definição de Pavis de discurso teatral enquanto "local de uma produção de significante" é justamente o que encontramos na poesia da autora de Em cada pedra um voo imóvel, como bem nos lembra Eduardo Prado Coelho. A respeito de Poesia 61, o crítico português afirma que, para aqueles poetas, "trata-se de formular uma concepção topológica do texto como lugar onde o sentido se produz" (COELHO, 1972, p. 265), ou, ainda, de "defender uma concepção estrutural do poema, em que cada elemento depende de todos os outros e apenas se define no espaço total e ilimitado do poema, através de uma rede muito densa de relações" (COELHO apud SILVEIRA, 1986, p. 18). São essas relações, postas em articulação pelo movimento interno do poema, que se distinguem como traços característicos de uma dramaturgia da poesia, segundo a qual o poema se torna lugar de desfamiliarização e de experimentação revolucionárias sobre a linguagem, assim como um palco de teatro.

Poesia e teatro parecem se encontrar, ainda, no movimento de "vaivém", ou de "paralelismo", identificado como característica estruturante da obra de Fiama por Silveira em seu estudo fundamental, Portugal maio de poesia 61. Por meio do "vaivém" pelos textos, a poeta sugere um jogo de leitura que leve em consideração a constante movimentação do leitor pelos versos dos poemas, num convite que o chama a participar ativamente do processo de significação, de transformação e de transporte de significados que se operam em sua obra. Com a declaração de que se trata de "recitações dramáticas", no título da seção de abertura de Em cada pedra um voo imóvel, Fiama abre espaço, ainda, para outra voz ecoar em seus textos: a do leitor a recitar os "dramas" que tem diante de si. Assim, sua escrita parece se exibir em processo, em ato, como drama que pressupõe, também, um processo e um percurso de leitura nosso, um movimento do leitor sobre esse palco de palavras.

Para Silveira,

os versos de Morfismos são vasos comunicantes. A capacidade de intervenção do leitor será tanto mais eficiente quanto mais perceber "na grafia dos espelhos' a articulação entre os versos de um poema e entre esse poema e os outros de todo o livro. [...][A] cada interpretação de um poema reaprendemos a interpretação do outro. (SILVEIRA, 1986, p. 65).

A partir desse movimento, percebe-se que os poemas estruturam, no limite, cenas da nossa leitura por seus versos, e esperam de nós a recitação dramática proposta desde 1958. As "recitações", portanto, implicam que sejamos o "leitor único", como na cena de leitura-a-vir que instaura num brilhante poema de Cenas vivas:

Entre todas as presenças, eu esperei

Diadorim, Rio de Janeiro, vol. 20, n. 1, p, 51-60, jan-jun. 2018. 
a do leitor. Quis ver-lhe os cílios

tremerem com a mancha poética.

Na cena doméstica que hoje vi,

a pequena cria abocanhada pelo cachaço,

levada pela gata, se puder, até ao Infinito,

é como o poema que o autor prende na boca.

Mas quem até aqui virá condoído da tortura

de ter um peso morto entre os meus dedos, poemas que não existem, autor sem som?

(BRANDÃO, 2000, p. 13).

Na proposta aos leitores, encontra-se mais um traço de dramaticidade e de performatividade da sua escrita. A "autora sem som" encena viva ao erguer um teatro da (sua) voz, oferecendo ao leitor sua re-citação incessante.

\section{Referências:}

BRANDÃO, Fiama Hasse Pais. Cenas vivas. Lisboa: Relógio d'Água, 2000.

. Recitações dramáticas. In: Em cada pedra um voo imóvel. Lisboa: Assírio \& Alvim, 2007, p. 15-53.

. Amago: antologia. Lisboa: Assírio \& Alvim, 2010.

COELHO, Eduardo Prado. Apresentação de um livro: (Este) Rosto. In: A palavra sobre a palavra. Porto: Portucalense, 1972.

MARTELO, Rosa Maria. Nomear os nomes. In: A forma informe: leituras de poesia. Lisboa: Assírio \& Alvim, 200, p. 125-129.

PAVIS, Patrice. Dicionário de teatro. Trad. Maria Lúcia Pereira, J. Guinsburg, Rachel Araújo de Baptista Fuser, Eudynir Fraga e Nanci Fernandes. São Paulo: Perspectiva, 2011.

PESSOA, Fernando. Obra poética: em um volume. Rio de Janeiro: Nova Aguilar, 1985.

SILVEIRA, Jorge Fernandes da. Portugal maio de Poesia 61. Lisboa: IN-CM, 1986.

. Apresentação. In: BRANDÃO, Fiama Hasse Pais. Cenas vivas. Lisboa: Relógio d’Água, 2000, s/p.

VASQUES, Eugénia. O manifesto teatro de Fiama. Metamorfoses, Lisboa, n. 6, p. 19-27, 2005. 